\title{
Kimya Endüstrisi Atık Suyunun Pilot Ölçekte Anaerobik/Anoksik/ Aerobik Membran Biyoreaktörde Arıtımı
}

\author{
The Treatment of a Chemical Industry Wastewater in Anaerobic/Anoxic/Aerobic Membrane \\ Bioreactor at Pilot Scale
}

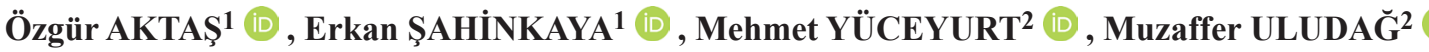 \\ ${ }^{1}$ İstanbul Medeniyet Üniversitesi, Biyomühendislik Bölümü, 34700, İstanbul, Türkiye \\ ${ }^{2}$ ENTA Arıtma Sistemleri LTD, Fazıl Kaftancıŏglu Cad, Seba İş Mrk., Seyrantepe, İstanbul, Türkiye
}

Öz

Bir kimya kompleksinin ortak arıtma tesisinin birincil arıtma çıkışından temin edilen atık suyun yaklaşık 16 m3 hacminde pilot ölçekte anaerobik, anoksik ve aerobik bölmelerden oluşan batık membran biyoreaktör sisteminde arıtımı yaklaşı sekiz ay boyunca takip edilmiştir. Çalışmada kullanılan atıksu, organik bileşiklerinin azot içermesi ve yüksek amonyum nedeniyle yüksek azotun yanı sıra üretimde kullanılan boya ve pigmentler nedeniyle yüksek renk de içermektedir. Atıksuda 1500-2000 mg/L seviyelerinde olan KOİ, MBR çıkışında \% 80-88 arasında değişen giderim verimleriyle $200-300 \mathrm{mg} / \mathrm{L}$ seviyelerine düşmüştür. Toplam azot (TN) ise 200-250 mg/L'den \% 70-80 arasında değişen giderim verimleriyle $40-50 \mathrm{mg} / \mathrm{L}$ seviyelerine indirilebilmiştir. TN'nin daha fazla düşürülememesi, girişteki yüksek TN nedeniyle geri devir arttırılsa bile denitrifikasyonun yeterli olmaması ve atık suyun 20-30 mgN/L kadar biyolojik olarak ayrıştırılamayan organik azot içermesine bağlanmıştır. Renk gideriminin ise \%78 14 verimle stabilize olduğu son 4 aylık dönemde, çıkış renk değerleri $136 \pm 64$ Pt-Co değerlerine kadar düşürülebilmiştir. Proses parametreleri kontrol edilerek tıkanma sorunu olmadan reaktörün işletimi başarıyla sağlanmıştır. Netice itibariyle çalışmalar göstermiştir ki A2O-MBR prosesi ile biyolojik olarak inert organik maddesi ve toplam azotu çok yüksek olan bir kimya endüstrisi atıksuyu için oldukça yüksek giderim oranları elde edilebilmektedir.

Anahtar Kelimeler: kimya endüstrisi atıksuyu; membran biyoreaktör; azot giderimi, A2O prosesi

\begin{abstract}
Wastewater obtained from the primary treatment effluent of a chemical complex was treated in a submerged membrane bioreactor consisting of anaerobic, anoxic and aerobic departments at pilot scale volume of $16 \mathrm{~m} 3$ and the treatment performance was followed for about eight months. The wastewater contained high nitrogen owing to nitrogen-bearing organic compounds and high ammonia and color due to dyes and pigments, which were used during production. COD ranging between 1500-2000 mg/L in the influent decreased to about 200$300 \mathrm{mg} / \mathrm{L}$ with the removal efficiencies of $80-88 \%$. Total nitrogen (TN) could be decreased to 40-50 mg/L from influent values of 200-250 $\mathrm{mg} / \mathrm{L}$ with removal efficiencies of 70-80 \%. TN could not be decreased to lower levels since denitrification could not be sufficient even if recirculation ratio was increased because of high $\mathrm{TN}$ in the influent and the presence of nitrogen-bearing inert organic matter corresponding to $20-30 \mathrm{mgN} / \mathrm{L}$. Effluent color decreased to $136 \pm 64 \mathrm{Pt}-\mathrm{Co}$ with the removal efficiencies of $78 \pm 14 \%$ during the final four months of operation. Reactor was successfully operated without fouling problems by controlling the process parameters. A2O-MBR process obtained quite high removal efficiencies for a chemical industry wastewater comprising high amounts of inert organics and total nitrogen.
\end{abstract}

Keywords: Chemical industry wastewater; membrane bioreactor; nitrogen removal, A2O process

\section{GİRIŞ}

Kimya endüstrisi biyolojik olarak ayrıştırılamayan veya zor ayrıştırılan çok çeşitli organik bileşikleri üretmekte veya üretimde ham madde olarak kullanmaktadır. Bu üretim neticesinde çoğunlukla atık suda biyotaya yabancı veya biyolojik olarak 
zor ayrıştırılabilen bileşikler görülmektedir. Bu bileşikler konvansiyonel arıtma tesislerinde uzaklaştırılamadıkları için doğaya salınabilmekte ve ciddi ekolojik zararlara yol açabilmektedirler [1]. Bunun yanı sıra, kimya endüstri atık suları yüksek organik madde, renk, azot, fosfor ve iletkenlik içerebilmektedir. Bu nedenle konvansiyonel fizikokimyasal çöktürme ve aktif çamur prosesleriyle arıtılmaları zararlı etkilerinin önlenmesi için genellikle yeterli olmamaktadır.

Ancak, konvansiyonel arıtma tesislerinde giderilmesi zor olan bazı organik bileşiklerin çamur yaşı daha yüksek olması nedeniyle membran biyoreaktörlerde (MBR) giderilmesi mümkün olabilmektedir [2]. Bununla birlikte MBR'lerin endüstriyel atıksulardan azot ve fosfor giderimini de artıracak şekilde anaerobik/anoksik/aerobik membran biyoreaktör (A2O-MBR) konfigürasyonuyla işletilmesiyle ilgili de literatürde çeşitli örnekler verilmiştir [3]. Örneğin bir çalışmada kömür işleme atık suyu farklı tanklarda anaerobik, anoksik ve takiben aerobik MBR prosesleri ile ve A2O-MBR prosesinin endüstriyel atıksularda karbonun yanı sıra azot ve fosfor gideriminde de kullanılabileceği gösterilmiştir [4]. Bir başka çalışmada da MBR sistemlerinde simültane azot ve fosfor gideriminin sağlanabildiğini gösterilmektedir [5]. A2O-MBR konfigürasyonu, azot ve fosfor gideriminin yanı sıra bazı dirençli organik bileşiklerin anaerobik mikroorganizmalar tarafından parçalanma ihtimalini de artırmaktadır [6]. A2O-MBR prosesi endüstriyel atıksuların geri kullanımı amaciyla da tercih edilebilmektedir [7]. Literatürde farklı endüstriyel atık suların birbirini takip eden anaerobik-anoksik-aerobik (A2O) proseslerle arıtılması ve ardından nanofiltrasyonla yeniden kullanılabilir kaliteye getirilmesi konusunda da çalışmalar mevcuttur [8]. MBR-NF teknolojisinin endüstriyel atık suların pilot-ölçekte arıtılması ve suyun geri kazanımı için kullanımına örnek teşkil eden çalışmalar da literatürde mevcuttur [9].

Literatürde karışık kimya endüstrisi atıksuyunun A2OMBR prosesiyle arıtılmasına dair bir çalışmaya rastlanmamıştır. Özellikle, çalışmanın pilot ölçekte ve gerçek atık suyla yapılması nedeniyle literatüre ve uygulayıcılara önemli katkı sağlaması beklenmektedir. Çalışmamızda, A2O-MBR prosesi için organik madde, azot, fosfor ve renk gibi parametrelerin atık suda giderilme performansı ve membran tıkanma özellikleri farklı işletme koşullarında test edilerek en iyi performans veren şartların belirlenmesi hedeflenmiştir. A2O konfigürasyonuyla yüksek azot ve fosfor konsantrasyonlarına sahip kimya endüstrisi atıksular1nın nutrient içeriğinin azaltılması amaçlanmıştır. Ayrıca, A2O prosesinde hem anaerobik hem de aerobik şartlarda biyolojik arıtmanın gerçekleşmesi, özellikle aerobik şartlarda degredasyona dirençli olan, ancak anaerobik şartlarda biyolojik olarak ayrıştırılabilen bazı organik bileşiklerin de konvansiyonel aktif çamur sistemlerine kıyasla degredasyonunun artırılması beklenmektedir. Elde edilecek A2O-MBR çıkış suyunun nanofiltrasyon veya ters ozmos ile ileri arıtma sonucunda proseste tekrar kullanılabilir kalitede olması beklenmektedir.

\section{MATERYAL VE YÖNTEM}

\subsection{Atıksu Özellikleri}

Çalışmada atıksu 5 farklı kimya fabrikasının ortak arıtma tesisinin birincil arıtma çıkışından temin edilerek pilot ölçekli tesise pompalanmıştır. Atık suyun elde edildiği tesislerde akrilik tow ve elyaf üretilmekte ve beyazlatılmaktadır. Üretimde kullanılan temel organik ham maddeler akrilonitril monomer, vinil asetat monomer, dimetilasetamid, optik beyazlatıcılar, çeşitli aminler, metil alkol, etil alkol, çeşitli esterler, çeşitli organik solventler ile çeşitli boya ve pigmentler olarak sıralanabilir. Bunun yanı sıra atık suyun organik bileşiklerinin azot içermesi ve yüksek amonyum nedeniyle yüksek azotun yanı sıra sülfat ve klorür nedeniyle yüksek iletkenlik ve üretimde kullanılan boya ve pigmentler nedeniyle de renk içerdiği görülmektedir (Tablo 1).

Tablo 1. Karışık kimya endüstrisi atık suyunun özellikleri

\begin{tabular}{ll}
\hline Parametre & Konsantrasyon \\
\hline KOİ, mgO2/L & $1571 \pm 375$ \\
Toplam N, mgN/L & $232 \pm 62$ \\
Toplam P, mgP/L & $1,4 \pm 0,7$ \\
Renk, Pt-Co & $703 \pm 234$ \\
İletkenlik, $\mu$ S/cm & $9243 \pm 1053$ \\
pH & $9,7 \pm 0,5$ \\
Yağ ve gres, mg/L & $6 \pm 4,4$ \\
Sülfat (mg/L) & $2008 \pm 285$ \\
Klorür (mg/L) & $1500 \pm 727$ \\
\hline
\end{tabular}

\subsection{Pilot Ölçekli Reaktör}

A2O-MBR prosesi için yaklaşık olarak toplam $16 \mathrm{~m} 3$ hacminde anaerobik, anoksik ve aerobik bölmelerden oluşan bir reaktör tasarlanmış ve buna bir batık membran modülü ve modülün yerleştirileceği bir membran tankı da ilave edilmiştir. Reaktörün temel özellikleri Tablo 2'de verilmiştir. Reaktörde atıksu sırasıyla anaerobik, anoksik, aerobik ve membran tanklarına alınmaktadır. Reaktörde tam karışım anaerobik ve anoksik tanklarda mekanik karıştıc1lar vasitasıyla, aerobik bölme ve membran tankında havalandırma ile sağlanmıştır. Anoksik tanktan anaerobik tanka çamur geri devri (R1), denitrifikasyonu sağlamak için aerobik tanktan anoksik tanka geri devir (R2) ve membran tankından aerobik tanka geri devir (R3) pompalar vasitasiyla 
gerçekleştirilmiştir. Reaktör bölmeleri ve geri devirlerin şematik gösterimi Şekil 1'de verilmiştir. MBR, çamurun yüklenerek devreye alınması ve stabil değerlerin elde edilmesinden sonra 8 ay süreyle 2-8 gün arasında değişen hidrolik bekleme sürelerinde (HRT) işletilmiştir.

Tablo 2. A2O Membran Biyoreaktör özellikleri

\begin{tabular}{ll}
\hline Anaerobik tank Hacmi & $1,69 \mathrm{~m} 3$ \\
Anoksik tank Hacmi & $4,8 \mathrm{~m} 3$ \\
Aerobik tank Hacmi & $9,6 \mathrm{~m} 3$ \\
Membran tank Hacmi & $1,92 \mathrm{~m} 3$ \\
Atıksu debisi & $10 \mathrm{~m} 3 /$ gün \\
Pompalanan Hava debisi & $60 \mathrm{~m} 3 /$ saat \\
SADm değeri & $0,3 \mathrm{~m} 3 / \mathrm{m} 2$. saat \\
Membran alanı & $50 \mathrm{~m} 2$ \\
Ak1 & $8-12 \mathrm{~L} / \mathrm{m} 2 /$ saat \\
\hline
\end{tabular}

PLC sistemi ile on-line olarak tüm sistem bilgisayar ortamında takip edilmiş, veriler otomatik olarak kaydedilmiştir. Reaktör içerisinde anaerobik tankta $\mathrm{pH}$, sıcaklık ve ORP, anoksik tankta ORP, aerobik tankta çözünmüş oksijen ve $\mathrm{AKM}$, membran ünitesinde $\mathrm{pH}$, sicaklık, AKM, seviye ve çıkışında bulanıklık değerleri sensörler vasıtası ile on-line olarak ölçülmüş ve veriler kaydedilmiştir. PLC sistemi kullanılarak debi on-line olarak kontrol edilmiş, böylece HRT online olarak ölçülebilmiştir. PLC sistemi kullanılarak geri devir pompaları on-line olarak kontrol edilmiş, böylece geri devir oranı kolayca istenen değerlere getirilebilmiştir. Akı değerleri ve zamana bağlı değişimleri PLC sistemi kontrol paneli üzerinden online olarak takip edilip, değişimler kayıt altına alınmıştır. TMP (Trans membrane pressure) ölçümleri de on-line olarak yapılıp kaydedilmiştir. Membranlar fasılalı filtrasyon ile işletilmiştir (5 dakika on, 1 dakika off). Membranlarda fiziksel temizleme amaciyla membrana verilen havanın birim membran alanı başına düşen debisini gösteren SADm değeri ilk etapta $0,5 \mathrm{~m} 3 / \mathrm{m} 2$.saat olarak tutulmuş olup, daha sonra $0,3 \mathrm{~m} 3 / \mathrm{m} 2$.saat değerine düşürülmüştür.

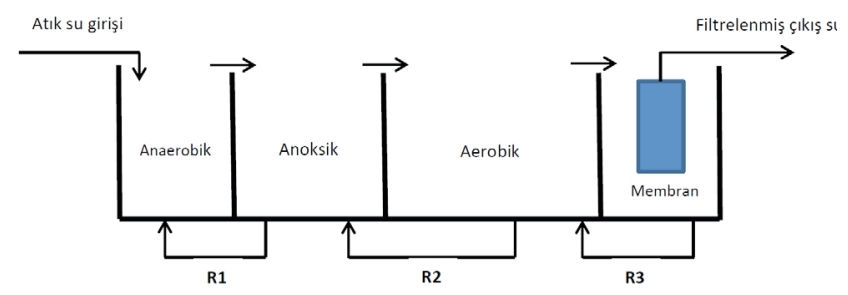

Şekil 1. A2O-MBR Prosesinin Şematik Gösterimi

Proses için en uygun olabilecek membran araştırılmış ve Mitsibushi Rayon Sterapore 5700 serisi Hollow fiber membranın kullanılmasına karar verilmiştir. Membran PVDF malzemeden üretilmiş olup $0,05 \mu$ gözenek çapına sahip olup, her bir fiberin çap 1,65 mm'dir. Her bir membran elemanının boyutları $18 \mathrm{~mm}$ derinlik, $594 \mathrm{~mm}$ genişlik ve 1 metre boy ve membran yüzey alanı ise $5 \mathrm{~m} 2$ olup, sistem için 10 membran elemanından oluşan ve toplam yüzey alanı $50 \mathrm{~m} 2$ olan membran modülü kullanılmıştır. Düz tabaka yerine hollow fibre membranın tercih edilmesinin sebebi, hollow fibre membranların birim hacimde daha fazla membran alanına sahip olmasıdır. Böylece hollow fibre membran kullanarak aerobik tanka kıyasla çok daha az hacme sahip olan ayrılmış bir membran tankında yüksek membran yüzey alanı kullanmak mümkün olmuştur.

MBR'de ak1 genellikle 8-12 LMH arasında tutulmuştur. TMP ise 165 mbar civarında sabitlenmiştir. Stabil kalan TMP membranda tıkanma olmadığını göstermiştir. Bu akılar için $0,3 \mathrm{~m} 3 / \mathrm{m} 2$.saat SADm değerinde havayla sıyırma yoluyla yapılan sürekli fiziksel temizleme ve fasılalı filtrasyon (5 dakika on - 1 dakika off) uygulanması yeterli olmuştur. Bu nedenle geri yıkamaya ve kimyasal temizlemeye ihtiyaç duyulmamıştır. 2-8 gün arasında değişen HRT'lerde çalışılmıştır. Denitrifikasyon performansını artırmak için anoksik tanka geri devir oranı 4'den 10'a kadar yükseltilmiştir.

İşletim süresince online ölçümlere ek olarak reaktör giriş ve çıkışında KOİ, nitrat, nitrit, toplam azot, amonyum azotu, fosfat, sülfat ve renk analizleri yapılmak üzere haftada 2-3 kez numune alınmıştır. Analizler standart metotlara [10] göre gerçekleştirilmiştir.

\section{BULGULAR VE TARTIŞMA}

\subsection{TMP ve Akı Değișimleri}

İşletim süresince MBR'de ak1 genellikle 8-12 LMH (L/m2/ saat) arasında tutulmuştur. TMP ise reaktör işletiminin ilk 2 aylık döneminde 20-70 mbar arasında değişirken bu dönemde yükselerek 165 mbar civarında sabitlenmiştir. Stabil kalan TMP membranda tıkanma olmadığını gösterir. Membranda kaçak olmadığında stabil akı ve basınç değerlerinin elde edilebildiği görülmüştür. 8-10 LMH arasındaki bu ak1lar için SADm değeri 0,3 m3/m2.saat olarak uygulanan havayla sıyırma yoluyla yapılan sürekli fiziksel temizleme ve fasılalı filtrasyon ( 5 dakika on - 1 dakika off) uygulanmas1 yeterli olmuştur. Bu nedenle geri yıkamaya ve kimyasal temizlemeye ihtiyaç duyulmamıştır.

Hidrolik bekleme süresi (HRT) ile günlük ortalama ak1 değerleri Şekil 2'de verilmiştir. Günlük ortalama ak1, HRT'nin 1-2 gün olduğu ilk 2 aylık dönemde 10-14 LMH arasında değişmekte iken ortalama membran basınc1 10-30 bar arasında kaydedilmiştir (Şekil 3). Bu dönemde önceki 
dönemden farklı olarak, SADm değeri $0,5 \mathrm{~m} 3 / \mathrm{m} 2$.saat'den $0,3 \mathrm{~m} 3 / \mathrm{m} 2$.saat'e düşürülmüştür ve bu değişikliğin membran basıncına olan etkisi takip edilmiştir. Daha sonraki süreçte ise akı 8-10 LMH arasına düşürülmüştür. Ayrıca HRT 2-10 gün arasında dalgalanmıştır. Membran basıncında ise zaman zaman membran kaçağı sorunları nedeniyle dalgalanmalar görülmüş olsa da genellikle 160-170 mbar civarında stabil tutulmuştur (Şekil 3).

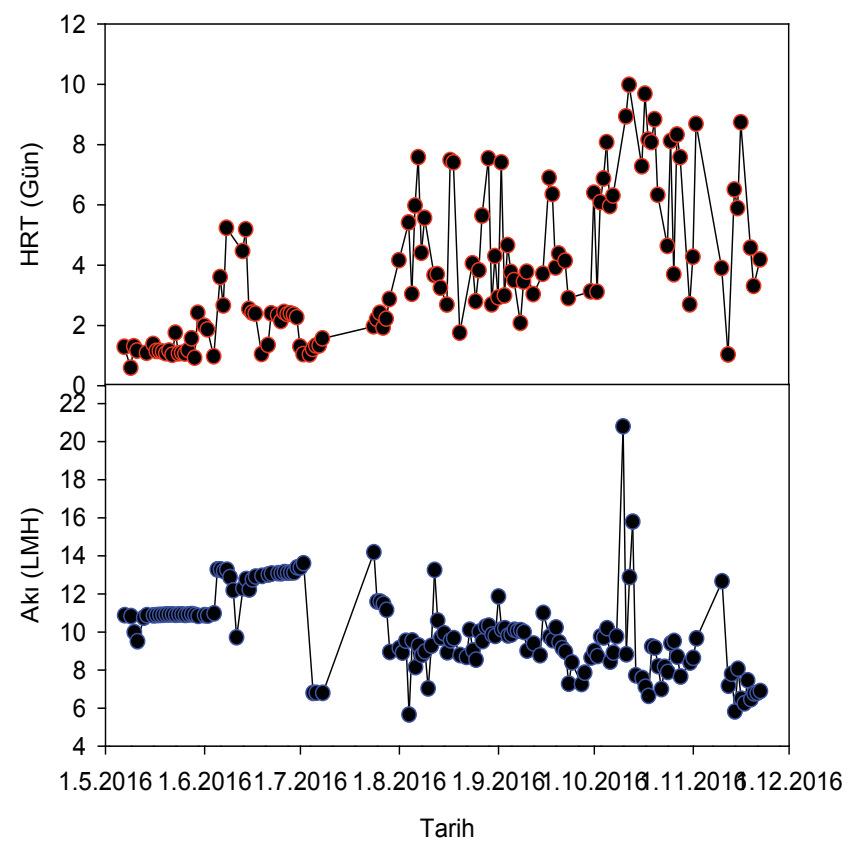

Şekil 2. İşletim sırasında HRT ve ortalama akı değişimi

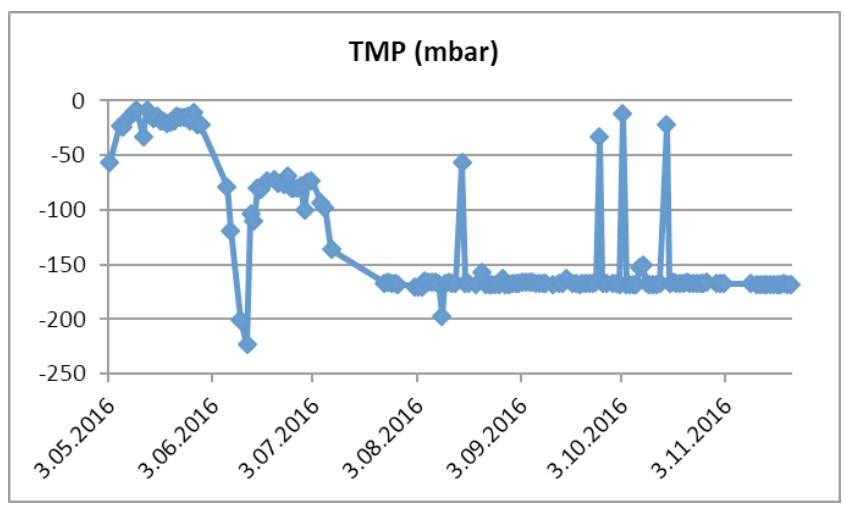

Şekil 3. İşletim sırasında TMP değişimi

İşletim esnasında süzüntüde ölçülen bulanıklık değerleri membran filtrasyonu esnasında membrandan askıda katı madde (AKM) kaçağının olup olmadığını gösterir. MBR çıkışında günlük ortalama bulanıklık değerleri Şekil 4'de verilmektedir. TMP'nin düşük olduğu (Şekil 3), yani membran filtrasyonunda sorun olmadığı dönemde ortalama bulanıklık genellikle 1 NTU'nun altında olup, belli aralıklarda küçük membran kaçaklarıyla 4 NTU'ya kadar çıkmaktadır. Zaman zaman 10-20 NTU seviyelerinde bulanıklığa yol açacak kaçaklar gözlenmiş ve bu dönemlerde membran onarılmıştır. Ancak bu dönemde çok büyük membran kaçağı olmadığını söylenebilir.

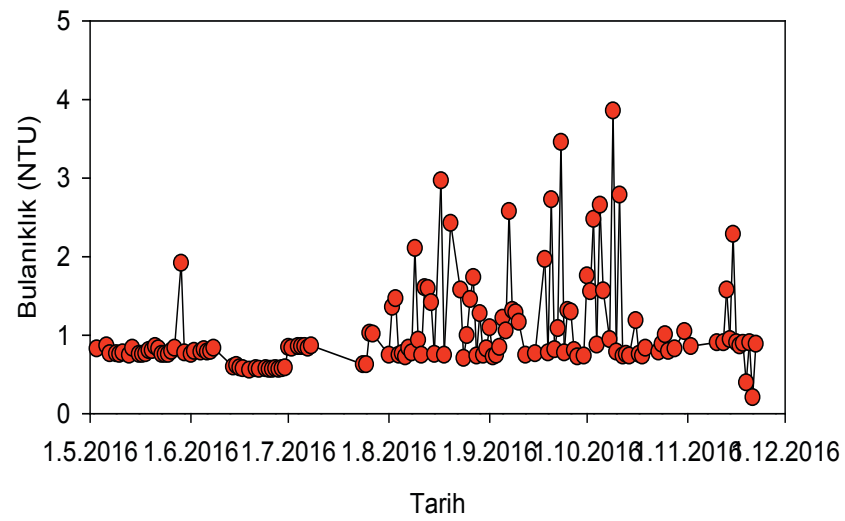

Şekil 4. MBR çıkışında günlük ortalama bulanıklık değerleri

Membran tankındaki AKM konsantrasyonu ise membran tıkanmasını etkileyen faktörlerden biridir. Membran tankındaki günlük ortalama AKM konsantrasyonları Şekil 5'de verilmektedir. Membran tankında AKM konsantrasyonu ilk dönemde 9000 mg/L seviyelerinden başlamış ve 11500 mg/ L'ye kadar yükselmiştir. Bu dönem başında ise fazla çamur çekilmesi nedeniyle AKM 7000-9000 mg/L seviyelerine düşse de 1 ay içerisinde tekrar 12000 mg/L ve üzerine yükselmiştir. Kullanılan membran için üretici tarafından önerilen 5000-15000 mg/L AKM değerleri arasında kalınmıştır.

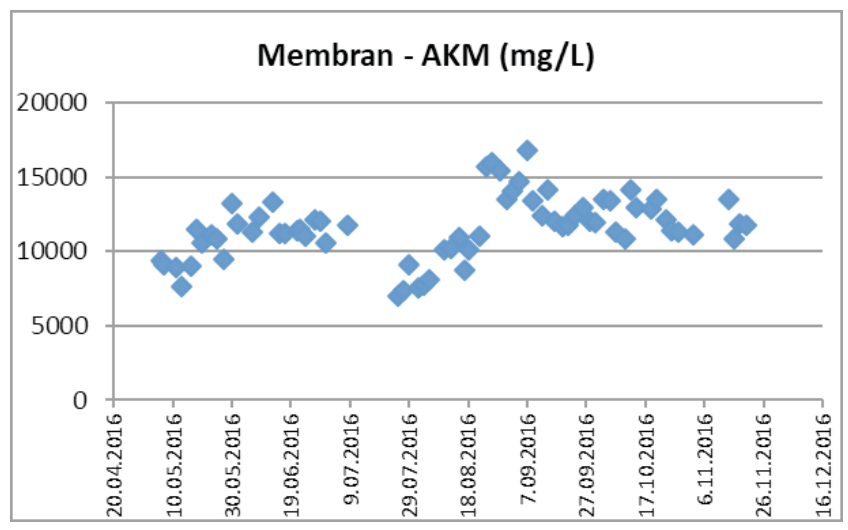

Şekil 5. Membran tankında AKM konsantrasyonları 


\subsection{Fizikokimyasal Parametrelerin Değișimi}

MBR'de işletme şartlarına bağlı olarak fizikokimyasal parametrelerde görülen değişimler sürekli olarak kaydedilmiş ve bunların kirletici parametrelerin giderimine olan etkileri analiz edilmiştir. MBR giriş ve çıkışındaki pH değerleri ile MBR aerobik tankındaki AKM konsantrasyonları sırasıyla Şekil 6 ve 7'de verilmektedir. Görüldüğü gibi MBR giriş $\mathrm{pH}$ 's1 10 civarından nitrifikasyonun da başlamasıyla MBR çıkışında 8 civarına düşmektedir. Reaktörde AKM 10000-13000 mg/L arasinda tutulmuş, bunun için günde yaklaşık olarak $350 \mathrm{~L}$ çamur atılmıştır. Dolayısıyla sistemin çamur bekleme zamanı (SRT) ortalama olarak 50 gün civarında kalmıştır.

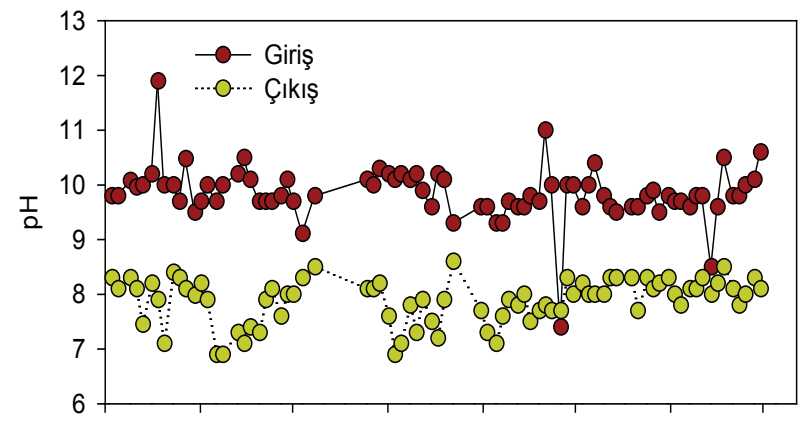

1.5.20161.6.20161.7.20161.8.20161.9.2016.10.2016.11.2016.12.2016

Tarih

Şekil 6. MBR giriş ve çıkışında $\mathrm{pH}$ değerleri

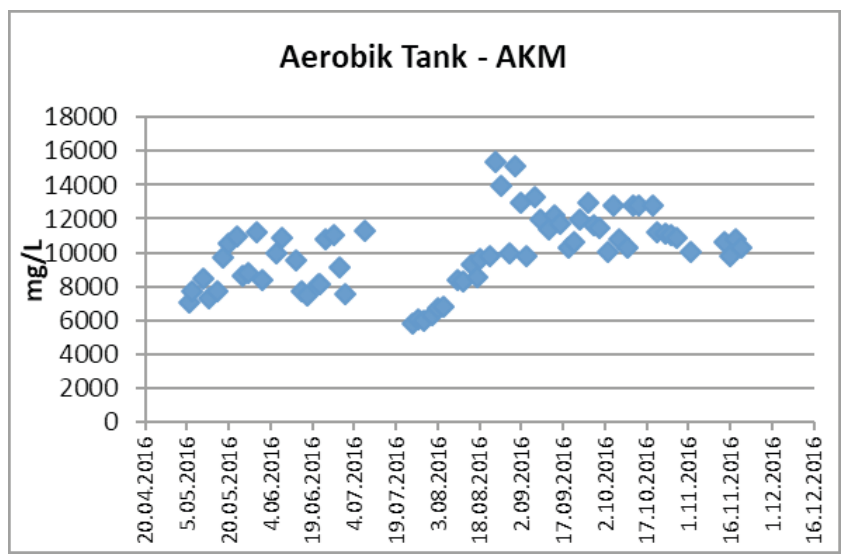

Şekil 7. Aerobik tankta AKM konsantrasyonları

A2O prosesinde anaerobik ve anoksik tanklarda ORP, aerobik tankta ise oksijen konsantrasyonları büyük önem taş1maktadır. Bu nedenle bu parametreler sensörler ile online takip edilmekte ve PLC sistemiyle değerler otomatik olarak kaydedilmektedir. ORP için günlük ortalama değerler Şekil 8'de görülebilir. İlk dönemde anaerobik tankta ORP - 500 ile - 700 $\mathrm{mV}$ arasında değişirken, anoksik tankta ORP -400 ile -500
$\mathrm{mV}$ arasında değişmiştir. İçsel geri devir oranlarının artması ve aerobik tankta oksijenin zaman zaman artmasına bağlı olarak ORP anaerobik tankta - 200 ile - 700, anoksik tankta ise çoğunlukla -100 ile -500 arasında dalgalanmıştır. İçsel geri devir oranlarındaki değişimler Şekil 9'da verilmiştir. Son dönemlerde ORP'nin - 100'ün de üzerine çıkan değerlerde olması, denitrifikasyonu olumsuz etkilemiştir. Aerobik tankta ise çözünmüş oksijen $2 \mathrm{mg} / \mathrm{L}$ 'nin üstünde tutulmuştur.

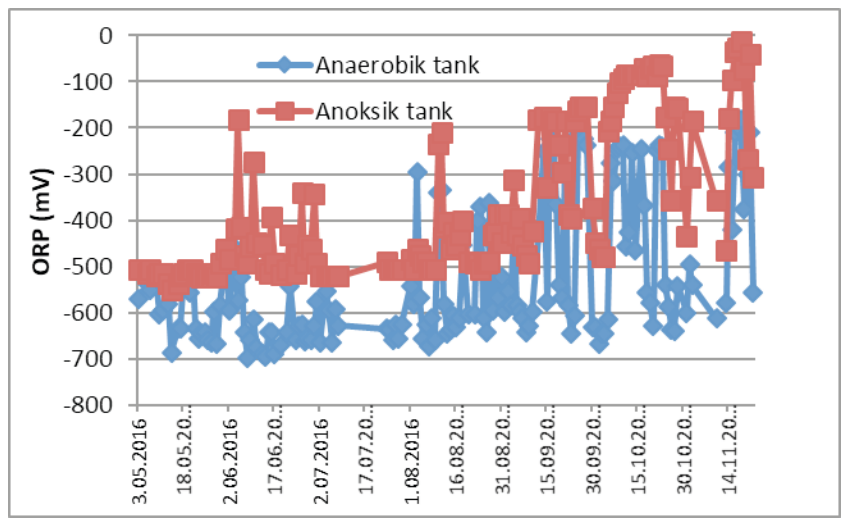

Şekil 8. Anaerobik ve anoksik tanklarda ORP değişimi

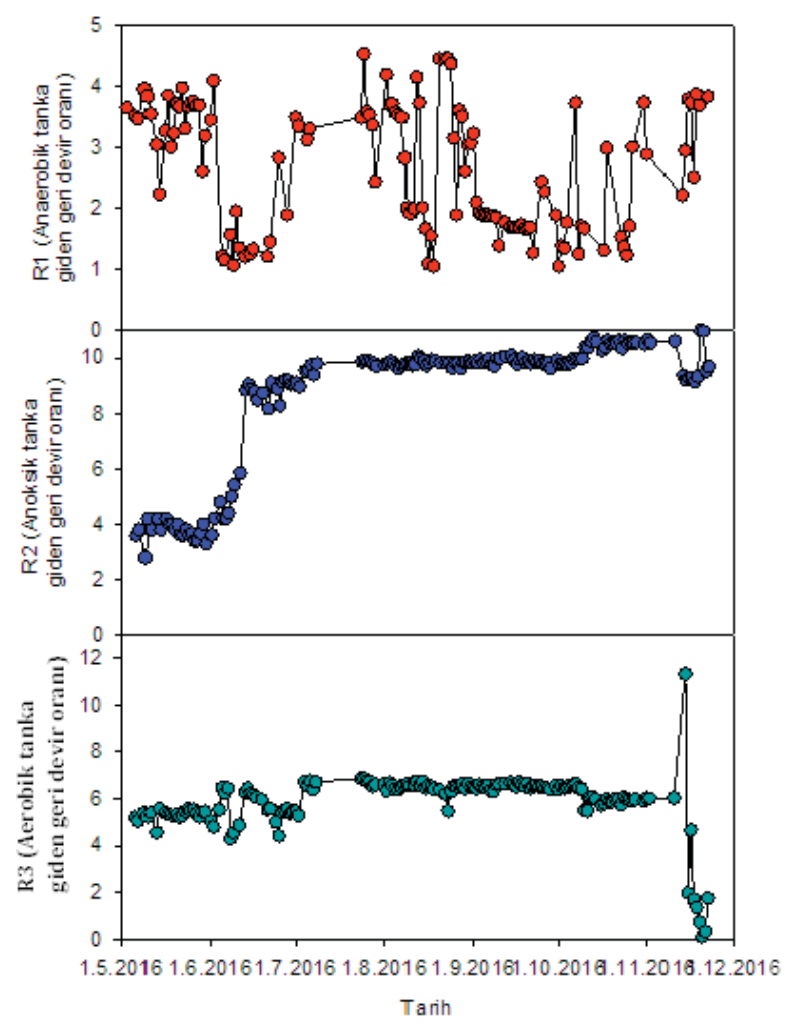

Şekil 9. İçsel geri devir oranları R1: anoksik tanktan anaerobik tanka, R2: aerobik tanktan anoksik tanka, R3:membran tankından aerobik tanka 


\subsection{Organik Madde, Azot ve Renk Giderimi}

MBR'de kirletici giderim performans1 parametrelerin s1klıkla ölçülmesiyle takip edilmiştir. Genellikle 1500-2500 mg/L arasında ölçülen KOİ giriş değerleri (ortalama 1960 $\pm 550 \mathrm{mg} / \mathrm{L}$ ), çıkışta yüzde 80-88 arasında değişen giderim verimleriyle $250-300 \mathrm{mg} / \mathrm{L}$ seviyelerine (ortalama $260 \pm 40$ $\mathrm{mg} / \mathrm{L}$ ) düşmüştür. MBR giriş ve çıkışında ölçülen KOİ değerleri Şekil 10'da görülebilir. MBR girişinde KOİ değerleri önemli ölçüde dalgalansa da MBR çıkışında KOİ diğer parametrelere kıyasla çok daha stabil kalmıştır ve büyük dalgalanmalar olmamıştır. Bunun sebebi çıkış suyundaki KOİ'nin biyolojik olarak giderilemeyen organik maddeden oluşmasıdır. MBR sisteminin biyolojik olarak giderilebilen organik maddeyi tamamıyla giderdiği düşünülmektedir. Çalışılan atık suda bulunan inert organik bileşikler ise ne anaerobik ne de aerobik şartlarda biyolojik olarak ayrıştırılamamıştır.

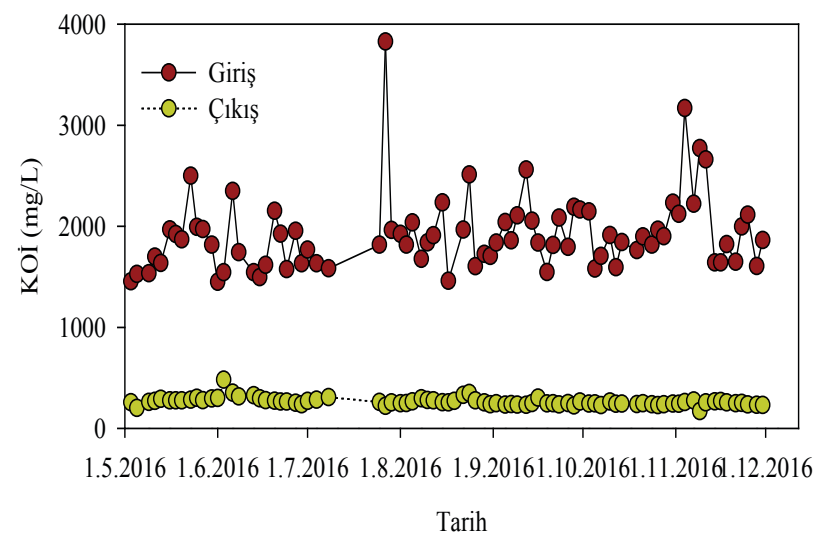

Şekil 10. MBR giriş ve çıkışında KOİ değerleri

Girişte 200-250 mg/L arasında değiş̧en (ortalama $229 \pm$ $44 \mathrm{mg} / \mathrm{L}$ ) toplam azot (TN) için giderim verimi işletmenin ilk ayı boyunca çok dalgalı bir seyir izlemiş ve sonrasında \% 70-80 arasında değişen giderim verilerine ulaşılmıştır. Reaktörün en verimli çalıştığı dönemlerde TN konsantrasyonu 40-50 mg/L seviyelerine indirilebilmiştir (Şekil 11). Ancak TN değerleri $30 \mathrm{mg} / \mathrm{L}$ 'nin altına indirilememiştir. Bunun başlıca nedeni denitrifikasyonun yeterli olmamasıdır. Giriş ve çıkıştaki NH4-N konsantrasyonları Şekil 12'de, reaktör çıkışındaki NO2-N ve NO3-N konsantrasyonları Şekil 13 'de verilmektedir. Denitrifikasyon performansını artırmak için anoksik tanka geri devir oranı 4'den 10'a kadar yükseltilmiştir (Şekil 9).

NH4-N konsantrasyonları girişte $100 \mathrm{mg} / \mathrm{L}$ civarında seyrederken, reaktörün işletmeye alınmasından sonraki 1 aylık dönemde ve işletme sorunlarının yaşandığı temmuz ayında çıkış konsantrasyonları dalgalanmış olmakla birlikte, genellikle MBR çıkışında NH4-N konsantrasyonları $1 \mathrm{mg} /$ L'nin altında sıfıra yakın değerlerde tespit edilmiştir (Şekil 12). Bu da MBR'da nitrifikasyonun başarıyla gerçekleştiğini göstermektedir. Ancak Şekil 9'da görüldüğü gibi aerobik tanktan anoksik tanka içsel geri devir oranları 10'a kadar yükseltilse de giriş TN konsantrasyonları yüksek olduğu için çıkışta nitrat konsantrasyonu denitrifikasyon veriminin en fazla olduğu dönemde dahi $15-20 \mathrm{mg} / \mathrm{L}$ seviyelerinde kalmıştır (Şekil 13) ve daha aşağı indirmek mümkün olmamıştır. Dolayısıyla, denitrifikasyon için biyolojik olarak ayrıştırılabilir organik madde miktarı yetersiz kalmış olup, anoksik tanka harici organik madde gibi bir elektron vericisinin ilavesi gerektiği sonucu çıkarılmıştır. Zira aerobik tankta biyolojik olarak giderilebilen organik maddelerin çoğu giderilmiş olduğu için denitrifikasyon oranını artırmak için aerobik tanktan anoksik tanka 10'a kadar yükseltilen geri devir oranları neticesinde (Şekil 9) anoksik tankta denitrifikasyon bakterilerinin kullanılabileceği yeterince biyolojik olarak ayrıştırılabilir organik maddenin kalmadığı anlaşılmaktadır. $\mathrm{Bu}$ nedenle, giriş suyunda $\mathrm{C} / \mathrm{N}$ oranları denitrifikasyon için fazlasıyla yeterli olsa da $\mathrm{A} 2 \mathrm{O}$ sisteminde yüksek geri devir oranlarında anoksik tankta biyolojik olarak giderilebilir organik madde miktarı nitratın tamamının giderimi için yeterli olmamıştır. Ancak buna rağmen geri devir oranının artırılması toplam azot giderimini $\% 80$ seviyelerine kadar çıarmıştır (Şekil 11).

Aynı dönemlerde MBR çıkışında TN 60-90 mg/L arasinda değişmiştir. Bu dönemlerde NH4-N'in neredeyse tamamen giderildiği dikkate alınırsa, çıkışta ölçülen TN'in önemli bölümünün biyolojik olarak ayrıştırılamayan organik azottan oluştuğu ortaya çıkmaktadır. MBR girişinde organik azot 100-150 mg/L civarında seyrederken (ortalama $125 \pm 50 \mathrm{mg} / \mathrm{L}$ ), MBR çıkışındaki 40-50 mg/L seviyelerindeki toplam azotun 20-30 mg/L'sinin organik azot olduğu söylenebilir (ortalama $26 \pm 8 \mathrm{mg} / \mathrm{L}$ ). Yani organik azotun yaklaşık \%20'si amonyuma dönüşmemekte ve bu nedenle nitrifikasyon-denitrifikasyon döngüsüne dahil olmamaktadır. Söz konusu kimya endüstrisi üretimde azot içeren organik maddeler kullanmaktadır ve bunların önemli bir bölümü biyolojik olarak ayrıştırılabilir olmadığı için TN değerlerinin A2O prosesiyle dahi hedeflenen $30 \mathrm{mg} / \mathrm{L}$ 'nin altındaki değerlere indirilmesi oldukça zor görülmektedir. Bu hedefe yaklaşabilmek için nitratın \% 100'e yakın verimle denitrifikasyonunun sağlanması gerekmektedir. 


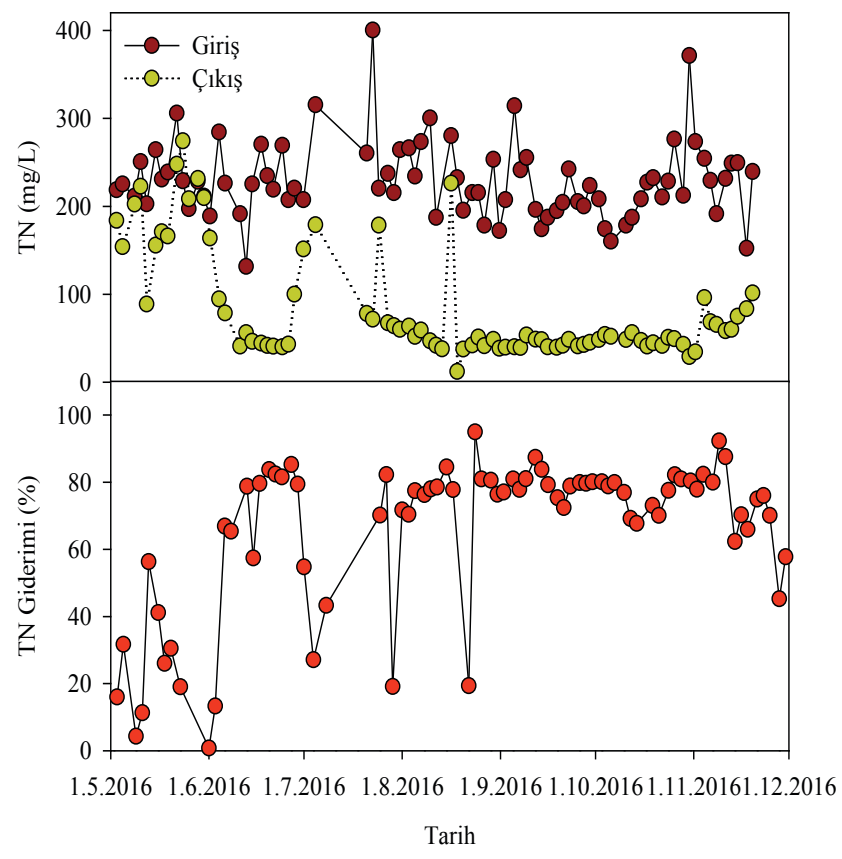

Şekil 11. MBR giriş ve çıkışında toplam azot konsantrasyonları ve giderimi

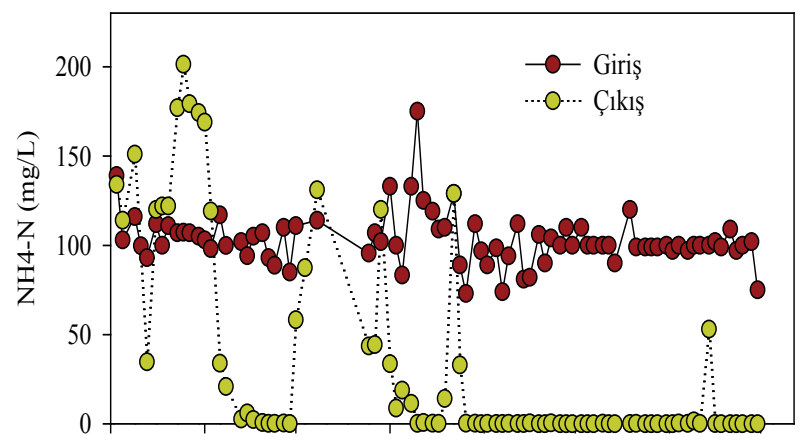

1.5.2016 1.6.2016 1.7.2016 1.8.2016 1.9.20161.10.20161.11.20161.12.2016

Tarih

Şekil 12. MBR giriş ve çıkışında amonyum azotu konsantrasyonları

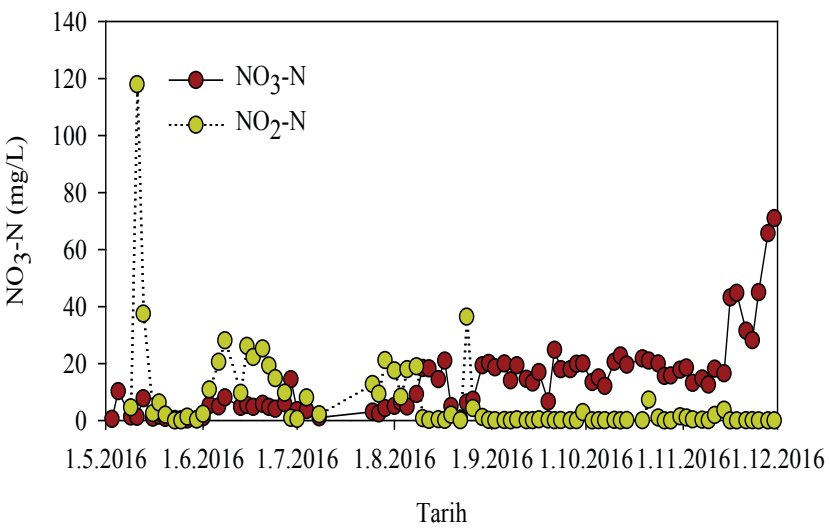

Şekil 13. MBR çıkışında nitrat ve nitrit azotu konsantrasyonları

Şekil 13'de görüldüğü gibi reaktörün işletilmeye başladığı ilk ay içerisinde nitrifikasyon gerçekleşmemiş, sonraki 2 ayda ise nitrit birikimi görülmüştür. Ancak daha sonra nitrifikasyonun tam olarak gerçekleştiği ve nitrit birikiminin artık söz konusu olmadığı görülmektedir. Nitrit konsantrasyonları bu dönemde çoğunlukla $1 \mathrm{mg} / \mathrm{L}$ 'nin altında (ortalama $0,7 \mathrm{mg} / \mathrm{L}$ ) ölçülmüştür. Reaktör sistemi her tarafı kapalı bir konteyner içerisine yerleştirilmiş olduğu ve kış aylarına gelmeden çalışma bitirildiği için reaktör içerisinde su sıcaklıkları $20-25^{\circ} \mathrm{C}$ arasında değişmiş ve nitrifikasyonu olumsuz etkileyecek şartlar oluşmamıştır. $\mathrm{Bu}$ nedenle işletilen A2O-MBR sisteminde azot giderimi açısından sınırlayıcı faktör nitrifikasyon değil, azotlu organik maddelerin amonifikasyonu ve bunun yanı sıra denitrifikasyon basamakları olmuştur. Şekil 14'te görüldüğü gibi alkalinite nitrifikasyon için yeterli olmuştur. Girişte 800$1200 \mathrm{mg} / \mathrm{L} \mathrm{CaCO} 3$ olan alkalinite tam nitrifikasyona rağmen $200 \mathrm{mg} / \mathrm{L}$ seviyelerinde kalmıştır. Denitrifikasyon esnasında oluşan alkalinite de MBR'de alkalinitenin yeterli seviyelerde kalmasında etkili olmuştur. Bu nedenle alkalinite ilavesine ihtiyaç duyulmamıştır. 


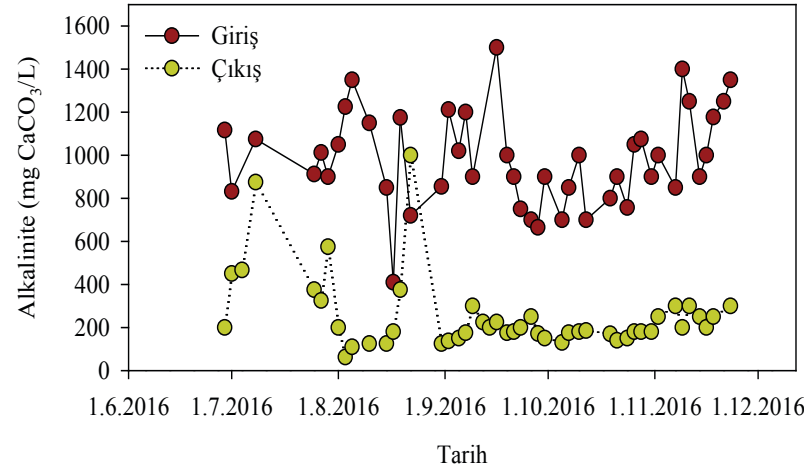

Şekil 14. MBR giriş ve çıkışında Alkalinite

MBR'de arıtılan kimya endüstrisi atıksuyu fosfor açısından zengin olmadığ da bir miktar fosfat giderimi sağlandığı için sistemde fosfor giderimi amaçlanmamıştır. Ancak yine de MBR çıkışında fosfat konsantrasyonları sürekli ölçülmüş ve çoğunlukla $1 \mathrm{mg} / \mathrm{L}$ 'nin altında PO4-P konsantrasyonları ölçülmüştür. MBR içerisinde organik madde ve azot gideren bakteriler için fosfatın yetersiz kalıp kalmadığını tespit etmek için Şekil $15^{\prime}$ te görüldüğü gibi reaktöre bazı dönemlerde fosfat ilave edilmiştir. Bu dönemlerde fosfat konsantrasyonu çıkşsta $20-30 \mathrm{mg} / \mathrm{L}$ seviyelerine kadar yükselmiştir. Ancak fosfat ilavesinin kesildiği dönemlerde çıkış fosfat değerlerinin tekrar $1 \mathrm{mg} / \mathrm{L}$ 'nin altına indiği görülmüsstür. Fosfat ilavesinin yapıldığı ve bu nedenle MBR içinde konsantrasyonlarının yüksek olduğu dönemlerde gerek organik madde gerekse de azot giderimi açısından ilave bir iyileşme görülmemiştir. Bu da göstermiştir ki, sistemde fosfor özellikle azot gideren bakteriler için sınırlayıcı besi maddesi olmamaktadır ve atıksu içerisindeki fosfor yeterli olmaktadır. $\mathrm{Bu}$ nedenle fosfor ilavesi kesilmiştir.

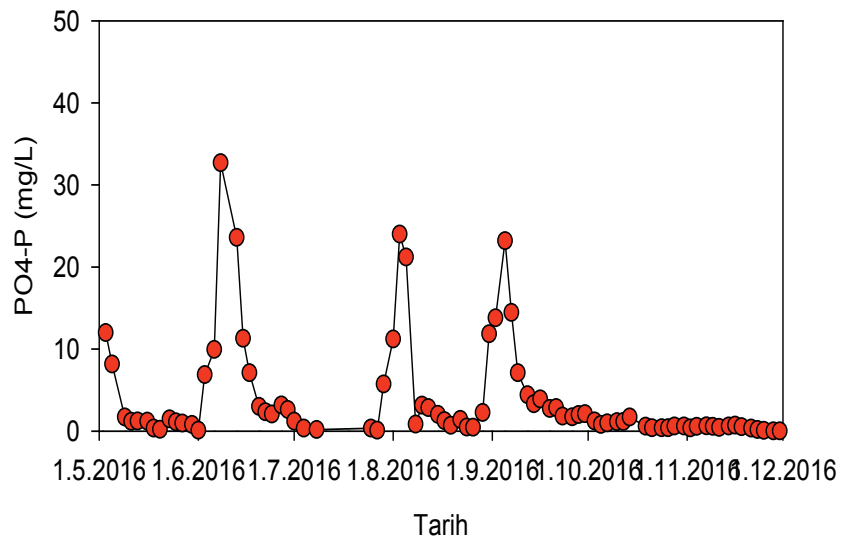

Şekil 15. MBR çıkışında fosfat konsantrasyonları

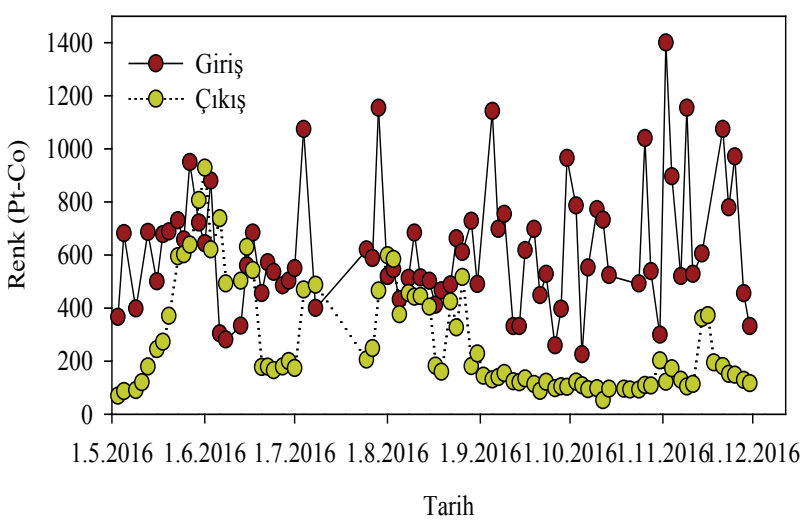

Şekil 16. MBR giriş ve çıkışında renk konsantrasyonları

MBR'nin kurulduğu kimya tesisinde önemli parametrelerden biri de renktir. Zira proseste boyar maddeler de kullanılmaktadır. MBR pilot tesisin tüm işletim dönemi boyunca giriş renk değerleri 223-2485 Pt-Co arasında dalgalanırken (ortalama $732 \pm 471 \mathrm{Pt}-\mathrm{Co}$ ), $\% 53 \pm 43$ ortalama giderim verimleri sonucunda çıkış değerleri $265 \pm 202$ Pt-Co civarında görülmüştür. Renk giderimleri Şekil 16'da verilmiştir. Görüldüğü gibi HRT'nin 1,5 gün civarında (Şekil 2) olduğu ilk 2 aylık işletim döneminde renk giderim performansı düşük gerçekleşmiş, ancak HRT’nin 4 gün civarına yükseltilmesiyle çıkış renk konsantrasyonları önemli ölçüde azalmıştır ve 4 aylık işletme döneminin sonunda 200 Pt-Co'ın altında stabil hale gelmiştir. Renk gideriminin $\% 78 \pm 14$ giderim verimleriyle stabilize olduğu son 4 aylık dönemde ise çıkış renk değerleri $136 \pm 64$ Pt-Co değerlerine düşmüş ve deşarj standartları sorunsuz olarak sağlanabilmiştir. Membran filtrasyon sorunlarının görülmediği bu dönemlerde renk, hedeflenen 280 Pt-Co değerinin altında seyretmiştir. Şekil 9'da görüldüğü gibi anoksik tanka geri devrin artırılmış olması ve Şekil 2'de görüldüğü gibi HRT'nin artırılmış olması renk gideriminin artmasında etkili olmuştur. Bu sonuçlar da göstermiştir ki kurulan pilot ölçekli A2O-MBR prosesi ile renk sorunu olan kimya endüstrisi atıksuyunda hedeflenen renk giderimleri sağlanabilmektedir.

\subsection{Sonuç ve Değerlendirmeler}

MBR, biyolojik olarak arıtımı zor olan böylesi bir kimya endüstrisi atıksuyu için oldukça yüksek sayılabilecek giderim verimleriyle ve membranda tıkanma sorunları yaşanmadan işletilebilmiştir. Atıksuda 1500-2000 mg/L seviyelerinde olan KOİ, MBR çıkışında yüzde 80-88 arasında değişen giderim verimleriyle 200-300 mg/L seviyelerine düşmüştür. 
HRT'nin yükseltilmesi ve içsel geri devrin artırılması KOİ gideriminde artışa yol açmamıştır. Bu arıtılamayan KOİ'nin biyolojik olarak inert olduğu ve daha fazla arıtılabilmesi için NF/RO gibi üçüncül bir arıtmanın gerekli olduğu sonucuna varılmıştır. Atıksuda 200-250 mg/L olan toplam azot için \% 70-80 arasında değişen giderim verilerine ulaşılmıştır. Reaktörün en verimli çalıştığ dönemlerde toplam azot (TN) konsantrasyonu $40-50 \mathrm{mg} / \mathrm{L}$ seviyelerine indirilebilmiştir, ancak TN değerleri hedeflenen $30 \mathrm{mg} / \mathrm{L}$ 'nin altına indirilememiştir. Bunun iki nedeni vardır, birincisi girişteki yüksek toplam azot nedeniyle her ne kadar geri devir arttırılsa bile denitrifikasyonun yeterli olmamasıdır. İkinci nedeni ise biyolojik olarak ayrıştırılamayan organik maddenin azot içermesi nedeniyle, MBR çıkışındaki toplam azotun 20-30 mg/L'sinin organik azottan kaynaklanmasıdır. Çıkışta TN'nin daha düşük seviyelere indirilebilmesi için çıkış suyunda hiç nitrat kalmaması ve denitrifikasyonun \%100 verime ulaşması gerekmektedir ki bu içsel geri devirli bir sistemde teorik olarak da mümkün değildir. Bu nedenle ileri arıtma TN giderimi açısından da şarttır. Netice itibariyle MBR çalışmaları göstermiş̧ir ki biyolojik olarak inert organik maddesi ve azotu çok yüksek olan böyle bir kimya endüstrisi atıksuyu için çıkış değerlerinin daha düşük seviyelerde tutulabilmesi ancak MBR'yi takip eden nanofiltrasyon veya gerekirse ters osmoz prosesleri kullanılmalıdır. Bir başka uygulama da MBR'a toz aktif karbon ilave edilmesi veya çıkış suyunun GAK filtreden geçirilmesi olabilir. Renk giderimi ise MBR performansının stabil hale geldiği 3 aylık işletim sonrasında $\% 78 \pm 14$ giderim verimleriyle $136 \pm 64$ Pt-Co çıkış değerlerine düşmüş ve hedeflenen $280 \mathrm{Pt}-\mathrm{Co}$ olan deşarj değerleri sorunsuz olarak sağlanabilmiştir.

Çalışmada pilot ölçekte bir örneği geliştirilen MBR'lerin klasik aktif çamur sistemlerine kıyasla en önemli avantajları zor ayrışan kirleticilerin daha iyi giderilebilmesi, membran filtrasyonunun sağladığı avantaj ile süzüntü suyunun partikül madde içermemesi ve bunlara bağlı olarak da yüksek kalitede yeniden kullanılabilme potansiyeli olan su üretebilmeleridir. Çalışmamızda geliştirilen MBR'de anaerobik, anoksik ve aerobik bölmeler yer almış ve içsel geri devir ile klasik A2O prosesinin yüksek oranlarda azot giderme avantajlarından da yararlanılmıştır. Örnek bir kimya endüstrisi atıksuyunun arıtımı için geliştirilen pilot ölçekte A2O-MBR prosesi klasik aktif çamur sistemlerine göre hem A2O prosesinin hem de MBR teknolojisinin avantajlarını sağlamıştır. Proses parametreleri kontrol edilerek tıkanma sorunu olmadan reaktörün işletimi başarıyla sağlanmıştır. Deşarj limitlerini sağlamanın yanı sıra, proses çıkışında elde edilen su, nanofiltrasyon veya ters ozmos proseslerinden geçirilerek yeniden kullanılma potansiyeline sahiptir.

\section{TEŞEKKÜR}

Bu çalışma TÜBITAK TEYDEB 7150663 nolu proje ile desteklenmiştir.

\section{KAYNAKLAR}

[1] Cao, S.M.S., Fontoura, G.A.T. Dezotti, M. ve Bassin, J.P. (2016). Combined organic matter and nitrogen removal from a chemical industry wastewater in a two-stage MBBR system. Environ. Technol., 37, 96-107.

[2] Judd, S. (2006). Principles and applications of membrane bioreactors in water and wastewater treatment. Elsevier Ltd, Oxford, UK.

[3] Xiao, K., Xu, Y., Liang, S., Lei, T., Sun, J., Wen, X., Zhang, H., Chen, C. ve Huang, X. (2014). Engineering application of membrane bioreactor for wastewater treatment in China: Current state and future prospect. Front. Environ. Sci. Eng., 8(6), 805-819.

[4] Zhao, W, Huang, X., Leeb, D., Wang, X. ve Shen Y. (2009). Use of submerged anaerobic-anoxic-oxic membrane bioreactor to treat highly toxic coke wastewater with complete sludge retention. J.Membr. Sci., 330, 57-64.

[5] Sun, F., Wang, X. ve Li, X., (2013). An innovative membrane bioreactor (MBR) system for simultaneous nitrogen and phosphorus removal. Process Biochem., 48, 1749-1756.

[6] Speece, R.E. (1996). Anaerobic Biotechnology for industrial wastewater treatments. Archae Press, Nashvillee, TN, USA.

[7] Hu, Y., Wang, X.C., Zhang, Y., Li, Y., Chen, H. ve Jin P. (2013). Characteristics of an A2O-MBR system for reclaimed water production under constant flux at low TMP. J. Membr. Sci., 431, 156-162.

[8] Grilli, S., Piscitelli, D., Mattioli, D., Casu, C. ve Spagni, A. (2011). Textile wastewater treatment in a bench-scale anaerobic-biofilm anoxic-aerobic membrane bioreactor combined with nanofiltration. J.Environ. Sci. Health A, 46, 1512-1518.

[9] Noronha, M., Britz, T., Mavrov, V., Janke, H.D. ve Chemiel, H. (2002). Treatment of spent process water from a fruit juice company for purposes of reuse: hybrid process concept and on-site test operation of a pilot plant.

[10] Standard Methods for the Examination of Water and Wastewater (2005). 21. bask1, American Public Health Association/American Water Works Association/Water Environment Federation, Washington DC, USA. 